\title{
WDD - Unit 1 Lesson Plan 1 - STEM.org Capstone
}

Ross Cohen ${ }^{1}$

${ }^{1}$ Affiliation not available

November 26, 2020

\section{Hosted file}

SLideshow WDD - Unit 1 Lesson Plan 1 - STEM-org Capstone.pdf available at https://authorea. com/users/378824/articles/495257-wdd-unit-1-lesson-plan-1-stem-org-capstone

Hosted file

WDD - Unit 1 Lesson Plan 1 - STEM-org Capstone.pdf available at https://authorea.com/users/ 378824/articles/495257-wdd-unit-1-lesson-plan-1-stem-org-capstone 